\title{
Model Studies on the Metal-Catalyzed Protein Oxidation: Structure of a Possible His-Lys Cross-Link
}

Yahua Liu, Gang Sun, Adrian David, and Lawrence M. Sayre

\section{Supporting Information}

\section{Table of Contents}

${ }^{1} \mathrm{H}$ NMR spectrum (300 MHz, $\mathrm{D}_{2} \mathrm{O}$ ) of 4-(2-aminoethyl)-1,2-dihydro-2-imidazolone ....... S2

${ }^{13} \mathrm{C}$ APT NMR spectrum (50 MHz, $\mathrm{D}_{2} \mathrm{O}$ ) of 4-(2-aminoethyl)-1,2-dihydro-2-imidazolone ..S3

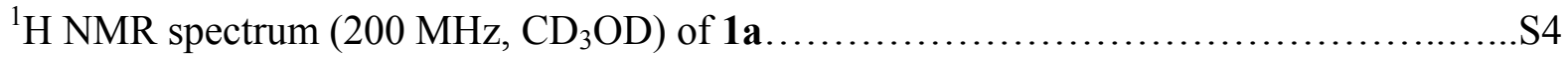

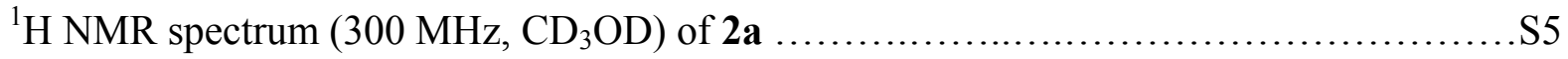

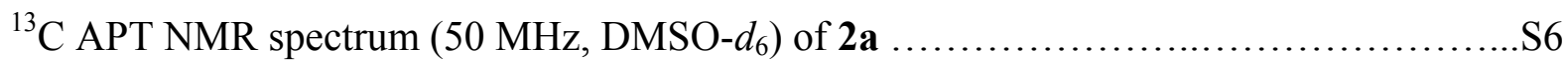

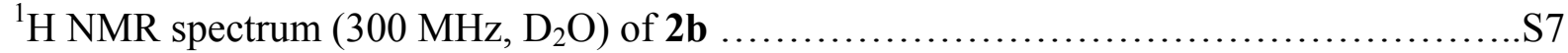

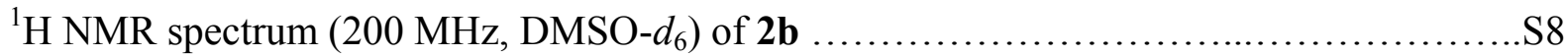

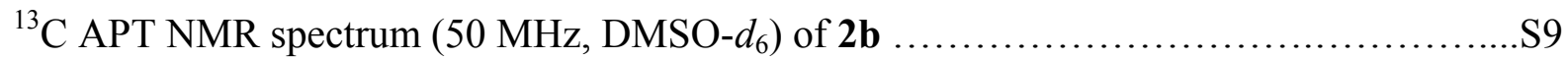

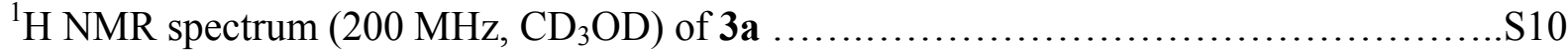

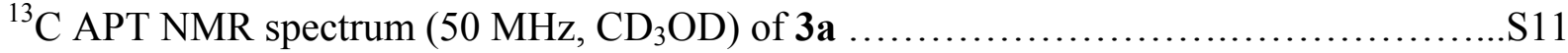

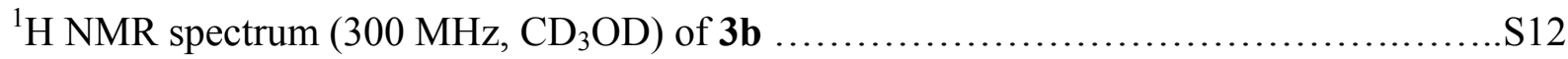

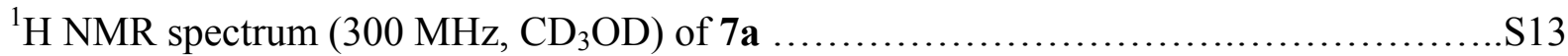

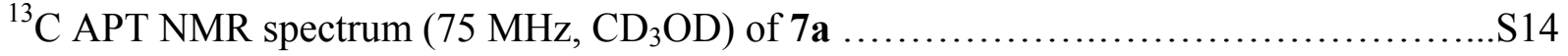

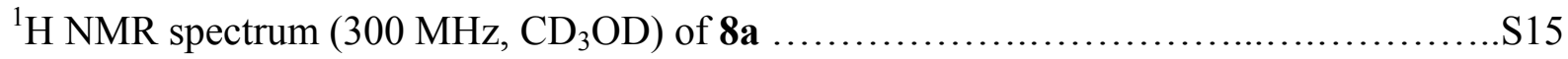

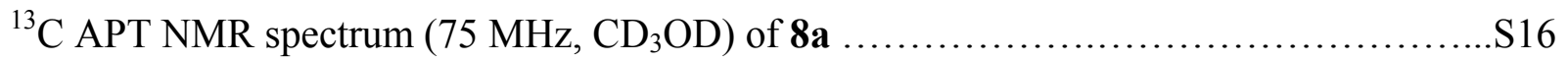

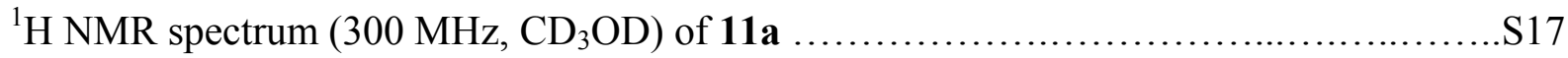

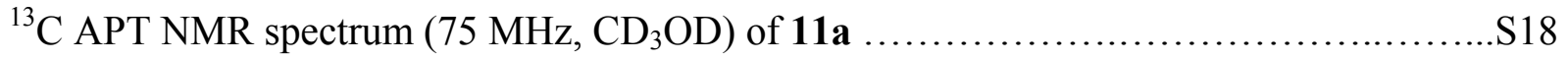




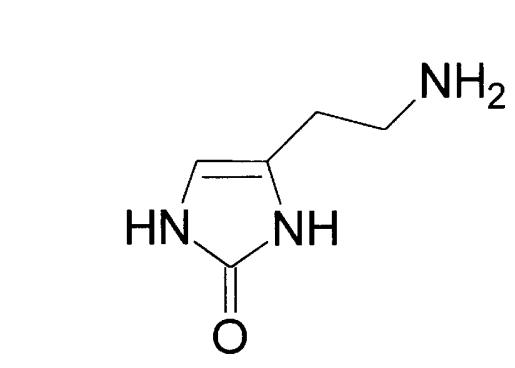

${ }^{1} \mathrm{H}$ NMR $(300 \mathrm{MHz})$ in $\mathrm{D}_{2} \mathrm{O}$

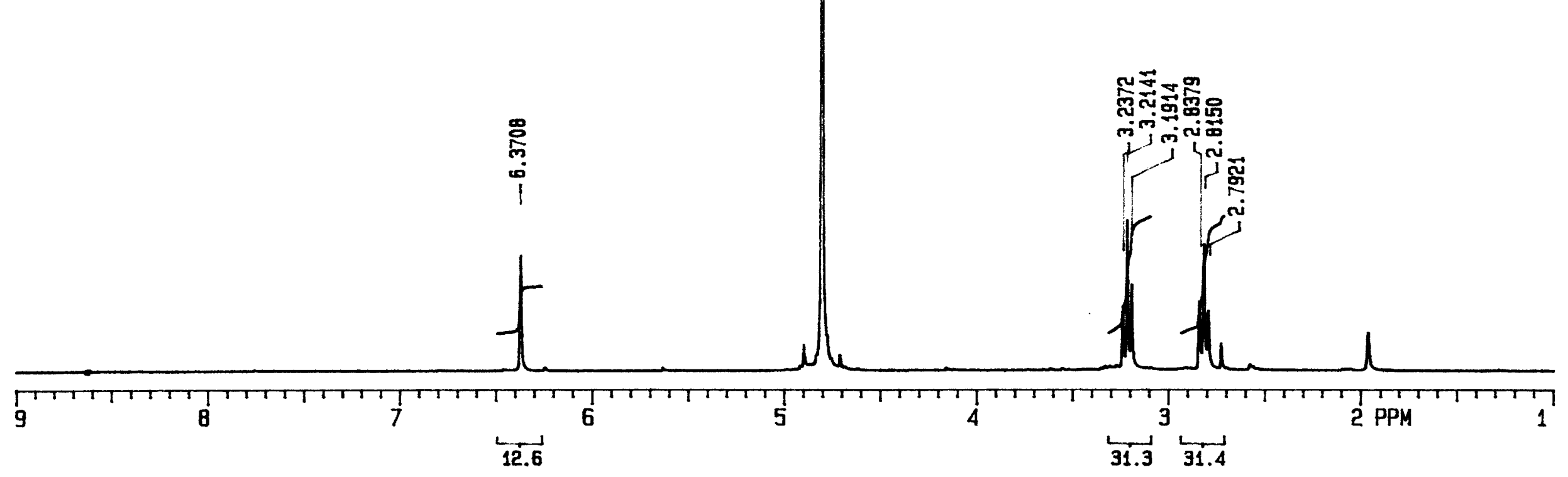




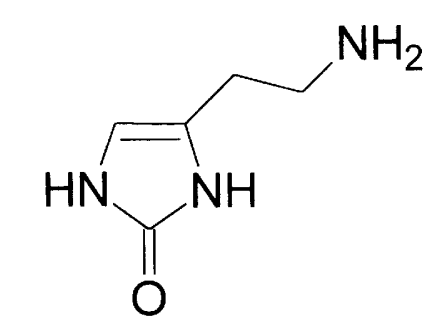

${ }^{13} \mathrm{C}$ NMR $(50 \mathrm{MHz})$ in $\mathrm{D}_{2} \mathrm{O}$

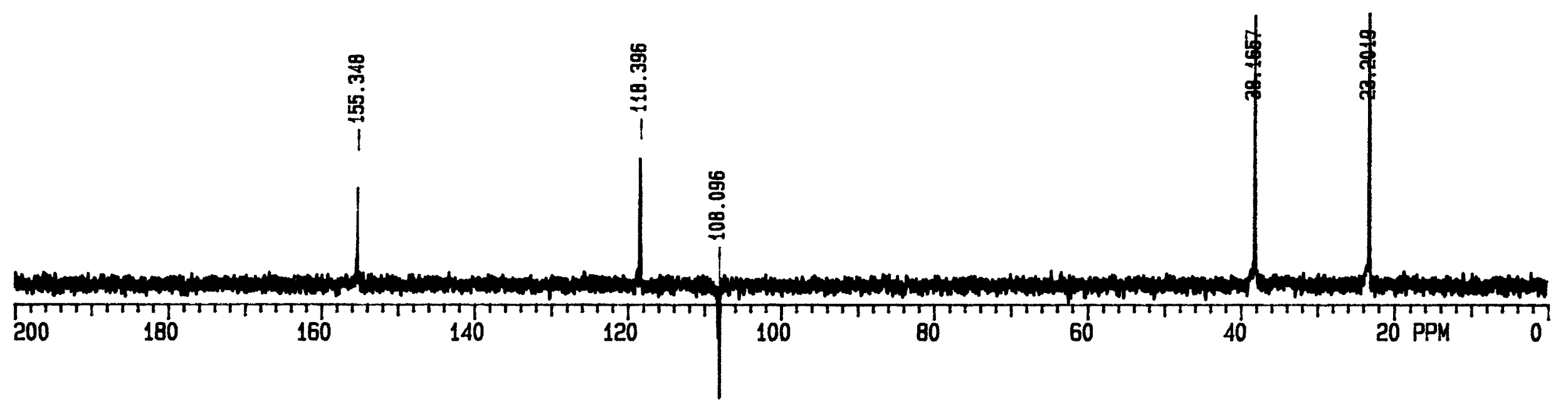




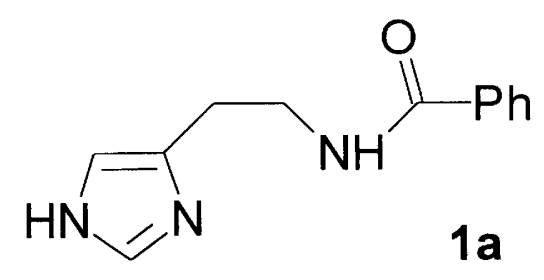

${ }^{1} \mathrm{H} N M R(200 \mathrm{MHz})$ in $\mathrm{CD}_{3} \mathrm{OD}$

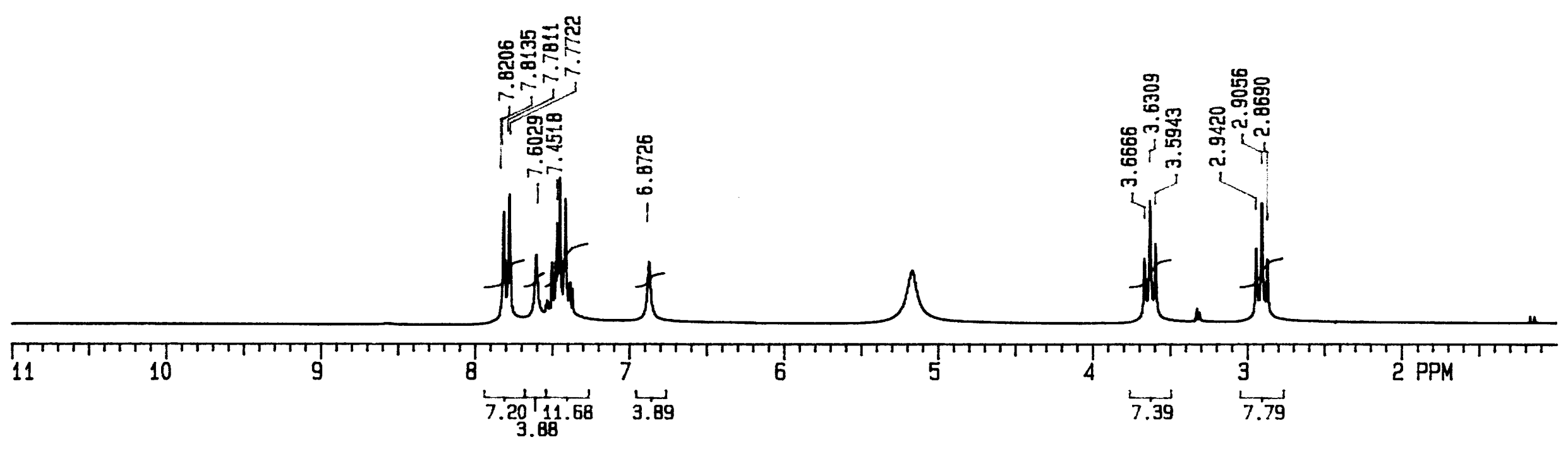




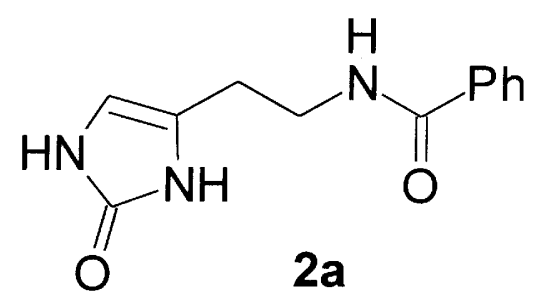

${ }_{1}^{1} \mathrm{H}$ NMR $(300 \mathrm{MHz})$ in $\mathrm{CD}_{3} \mathrm{OD}$

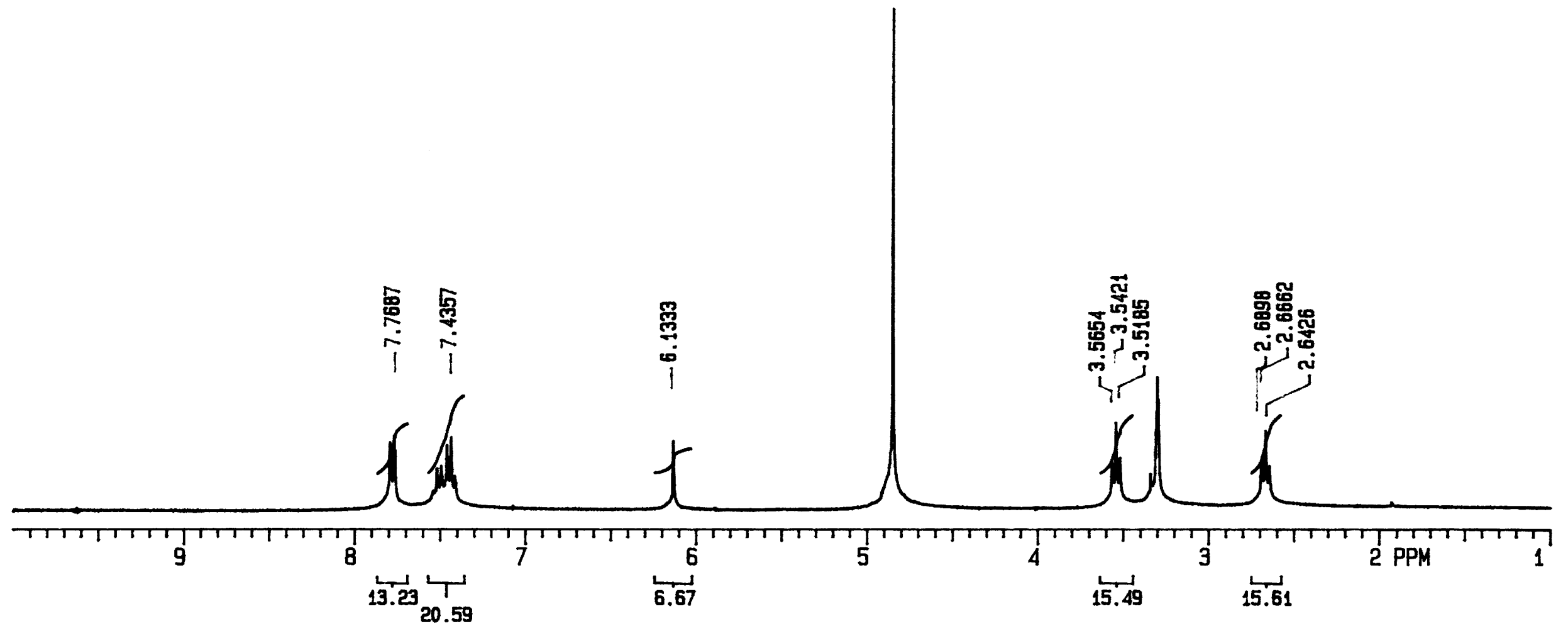




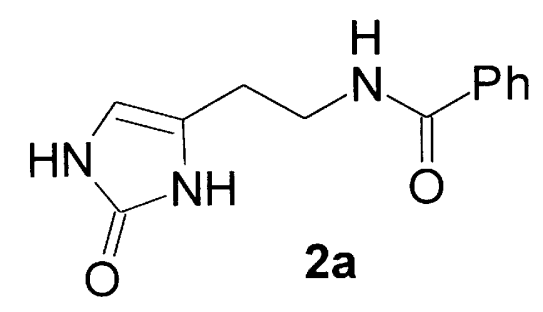

${ }^{13} \mathrm{C}$ NMR $(50 \mathrm{MHz})$ in DMSO- $d_{6}$

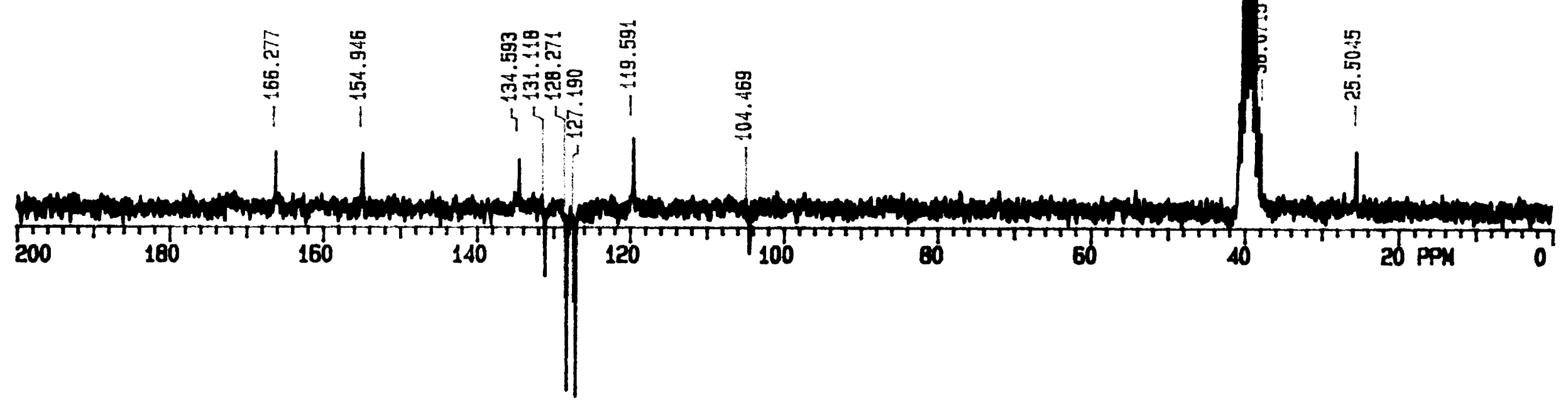




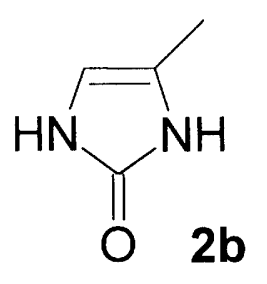

${ }^{1} \mathrm{H}$ NMR $(300 \mathrm{MHz})$ in $\mathrm{D}_{2} \mathrm{O}$

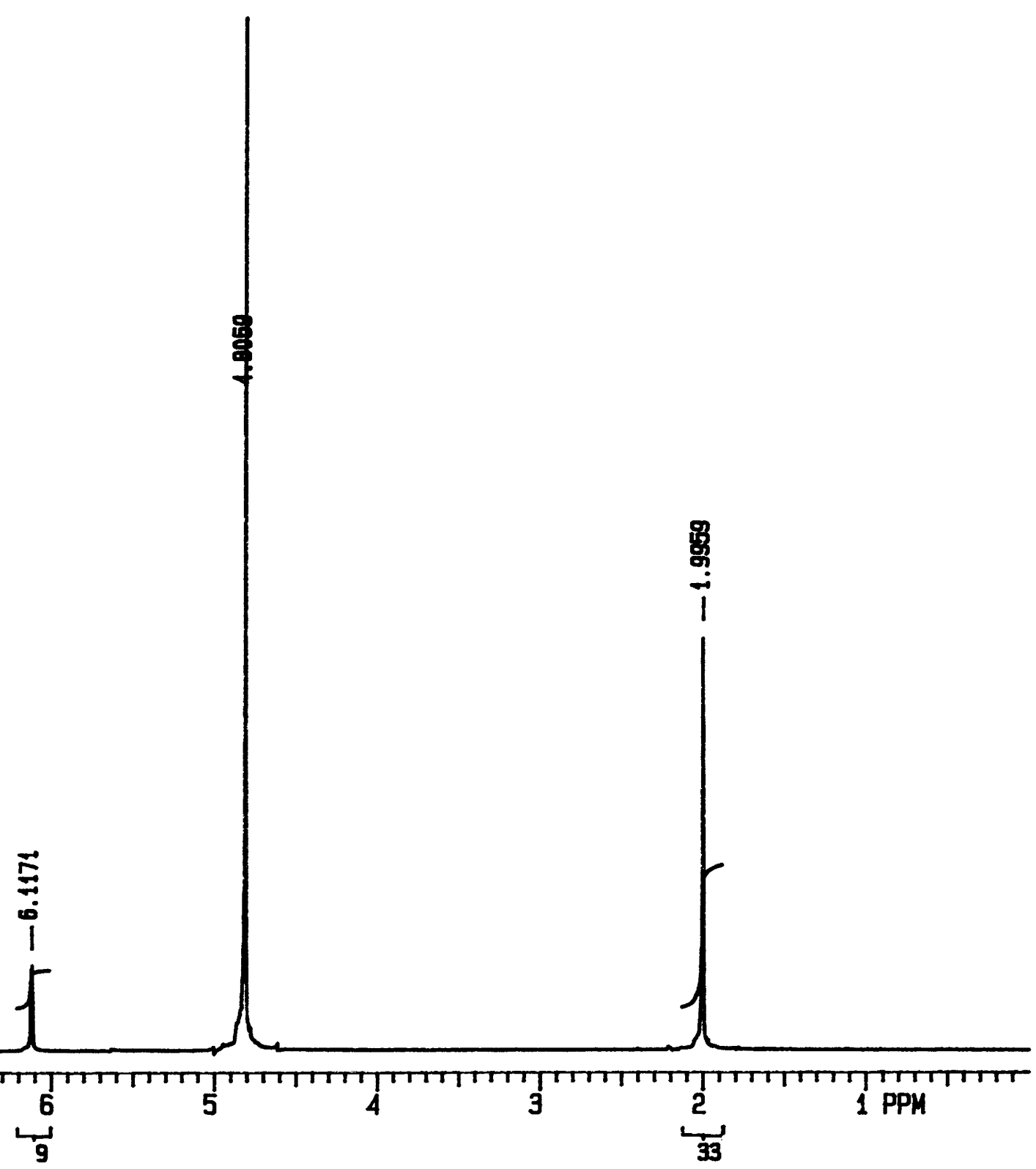




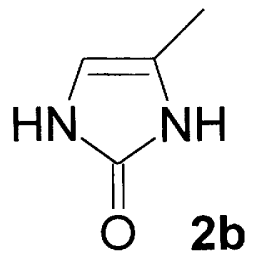

1H NMR (200 MHz) in DMSO- $d_{6}$

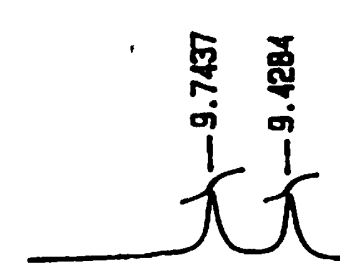

苛

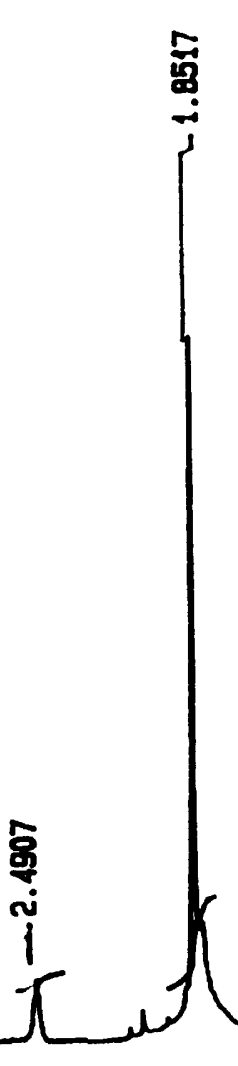

2

15.5 


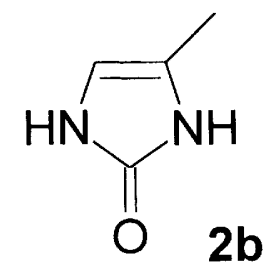

${ }_{13} \mathrm{C} \mathrm{NMR}(50 \mathrm{MHz})$ in DMSO- $d_{6}$

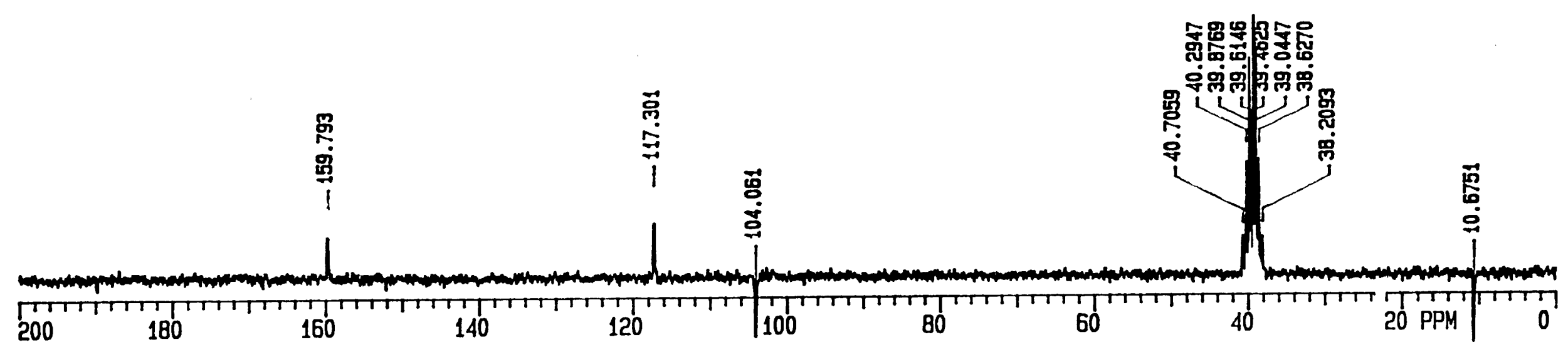




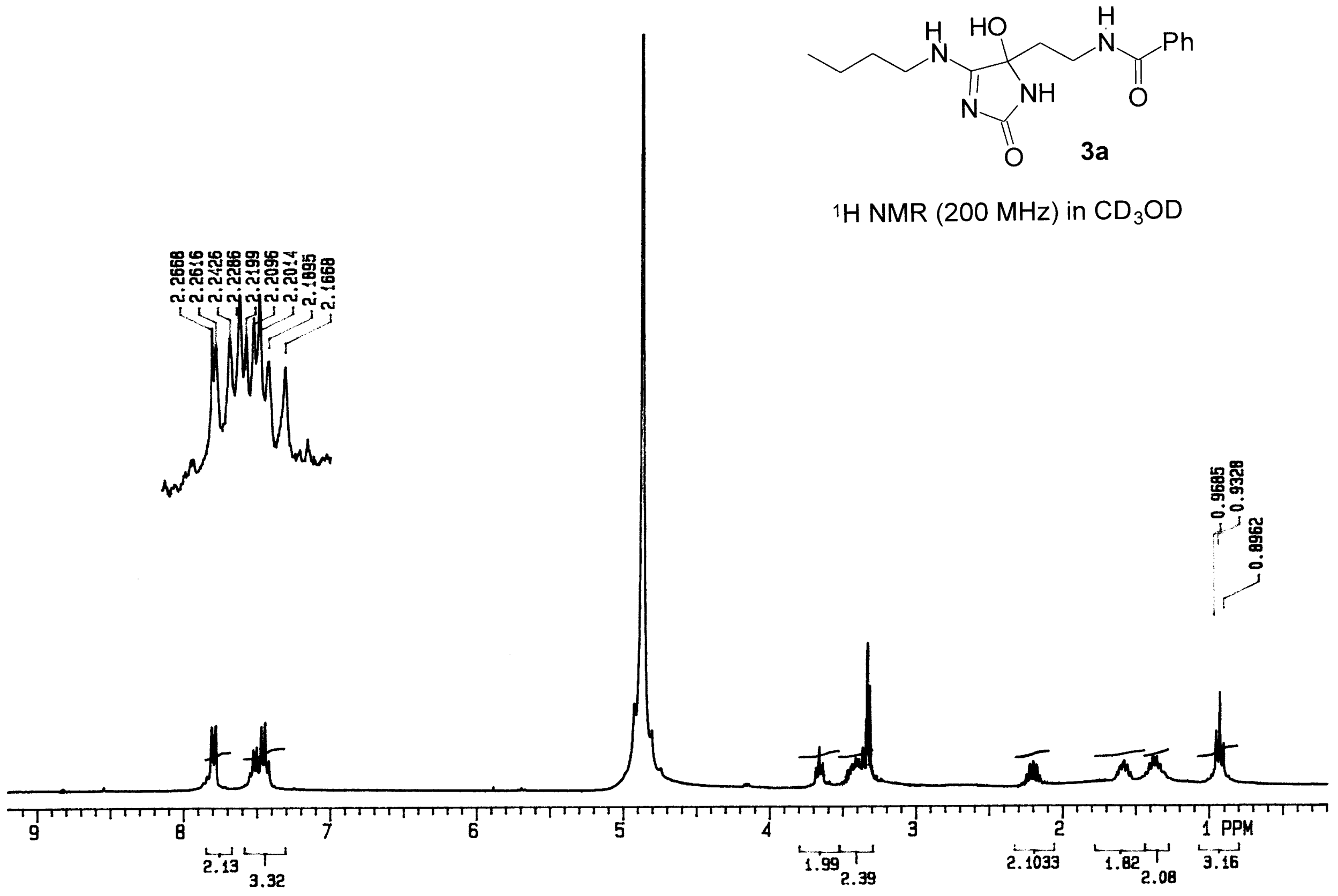




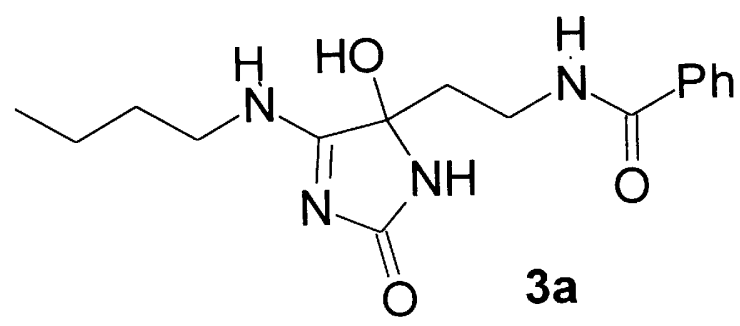

${ }^{13} \mathrm{C}$ NMR $(50 \mathrm{MHz})$ in $\mathrm{CD}_{3} \mathrm{OD}$

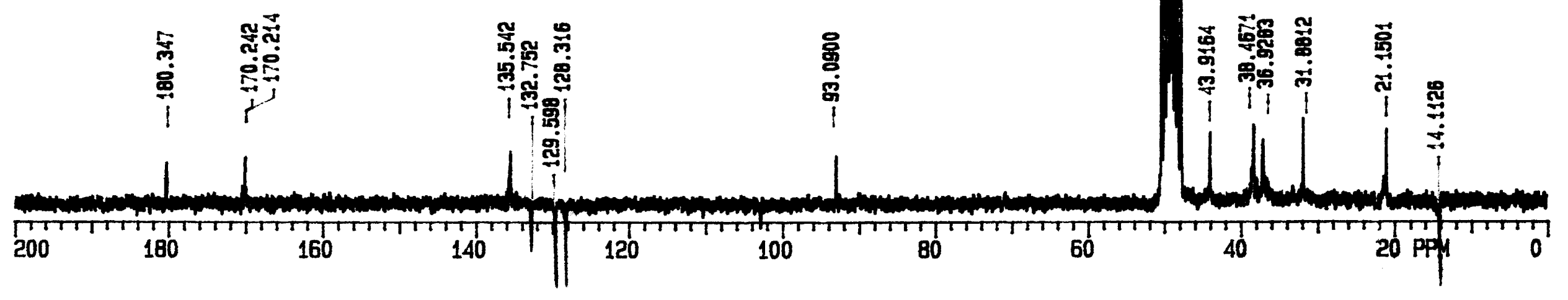




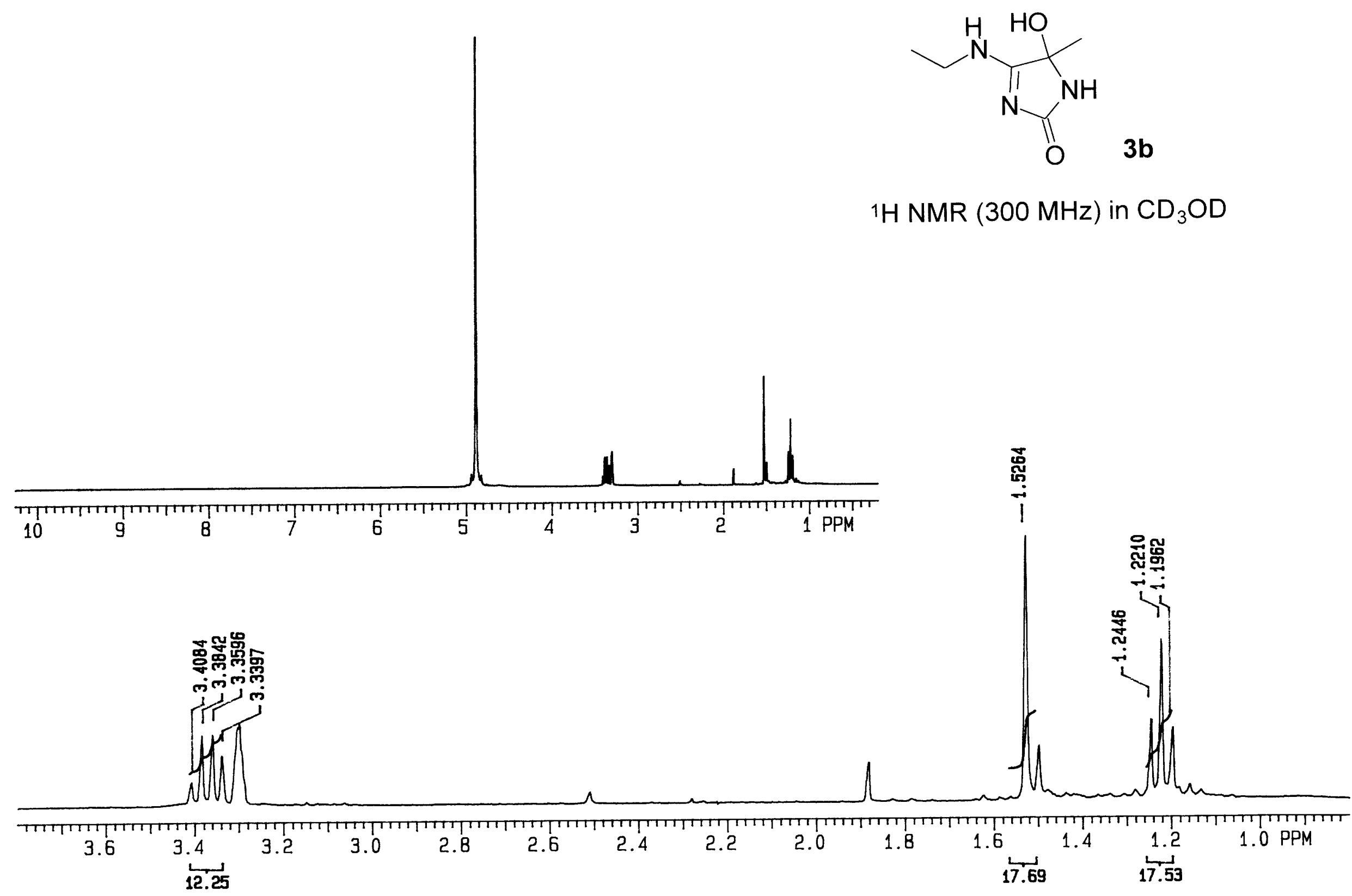




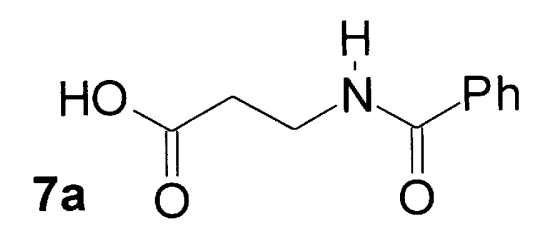

${ }_{1}^{1} \mathrm{H}$ NMR $(300 \mathrm{MHz})$ in $\mathrm{CD}_{3} \mathrm{OD}$

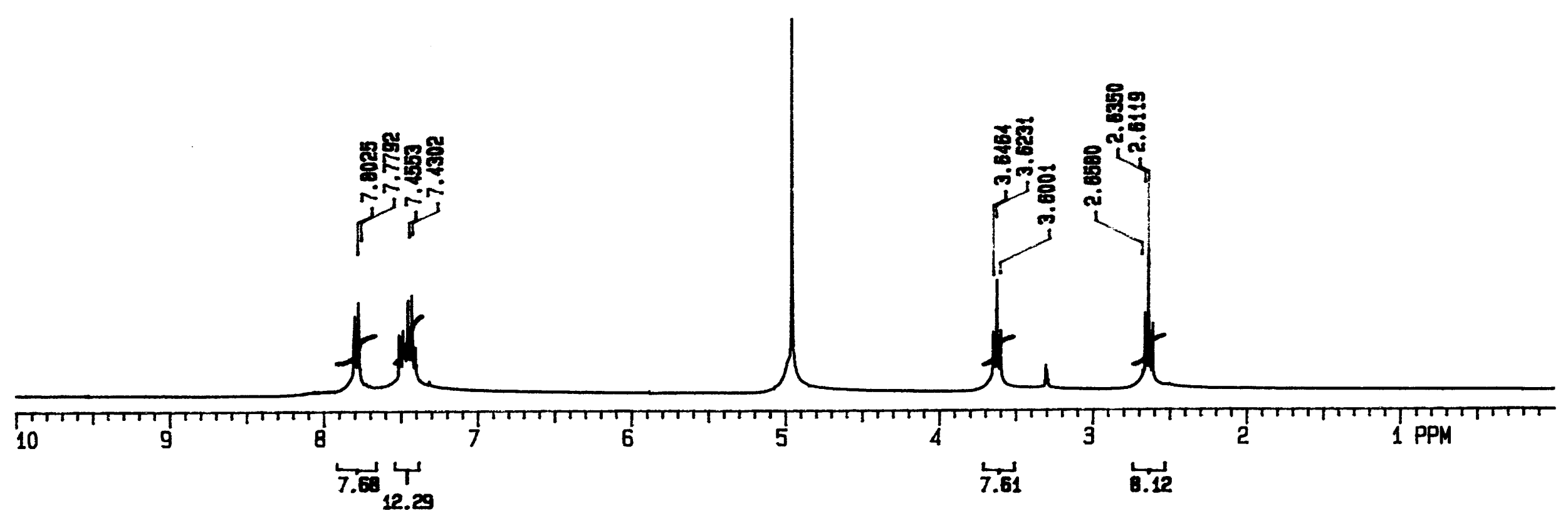




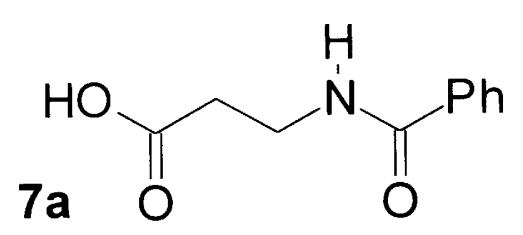

${ }^{13} \mathrm{C}$ NMR $(75 \mathrm{MHz})$ in $\mathrm{CD}_{3} \mathrm{OD}$

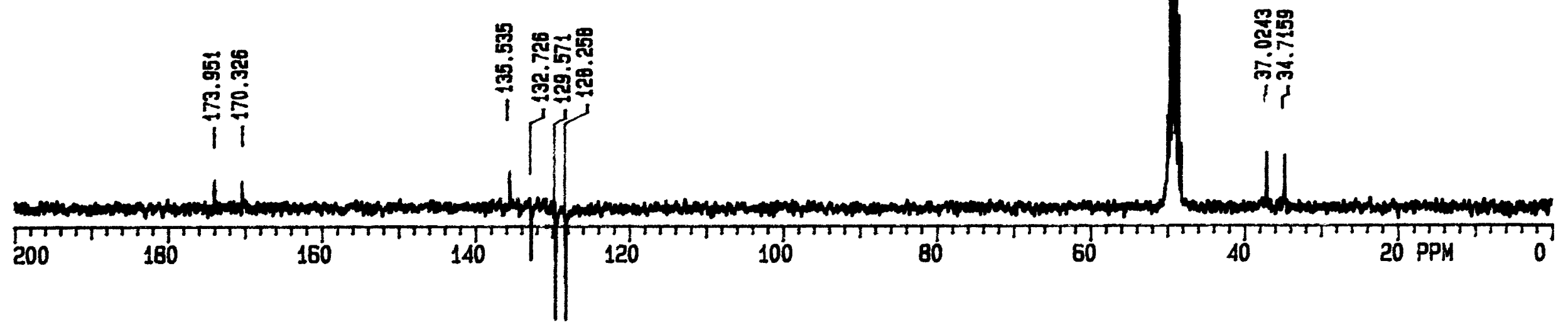




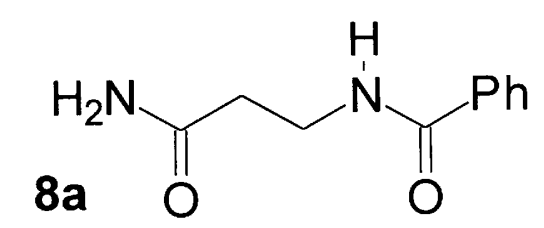

${ }_{1}^{1} \mathrm{H} \mathrm{NMR}(300 \mathrm{MHz})$ in $\mathrm{CD}_{3} \mathrm{OD}$

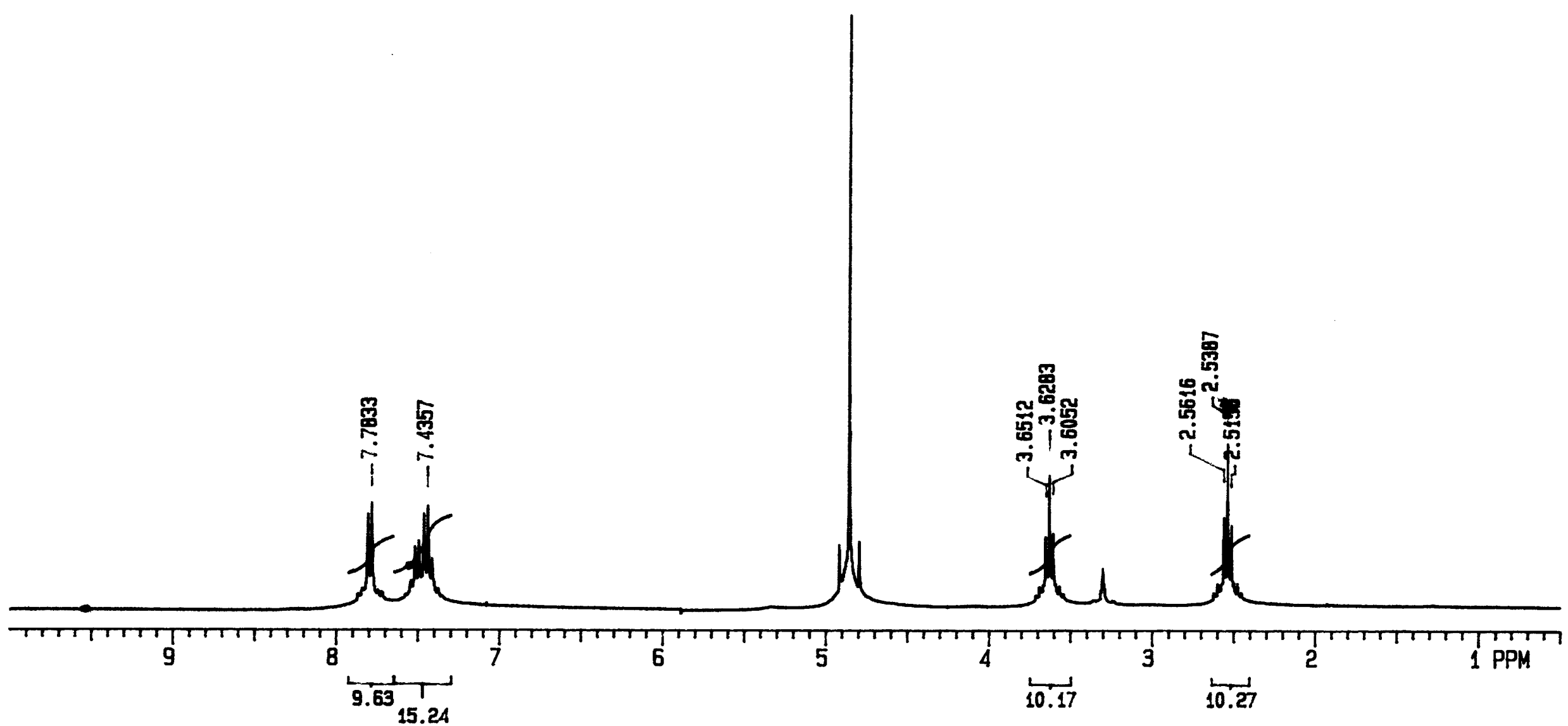




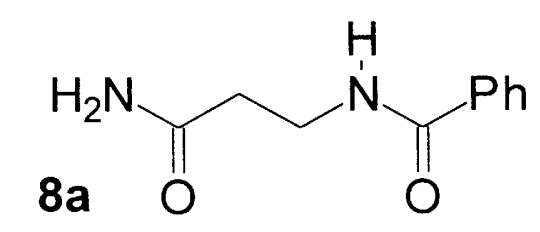

${ }^{13} \mathrm{C}$ NMR $(75 \mathrm{MHz})$ in $\mathrm{CD}_{3} \mathrm{OD}$

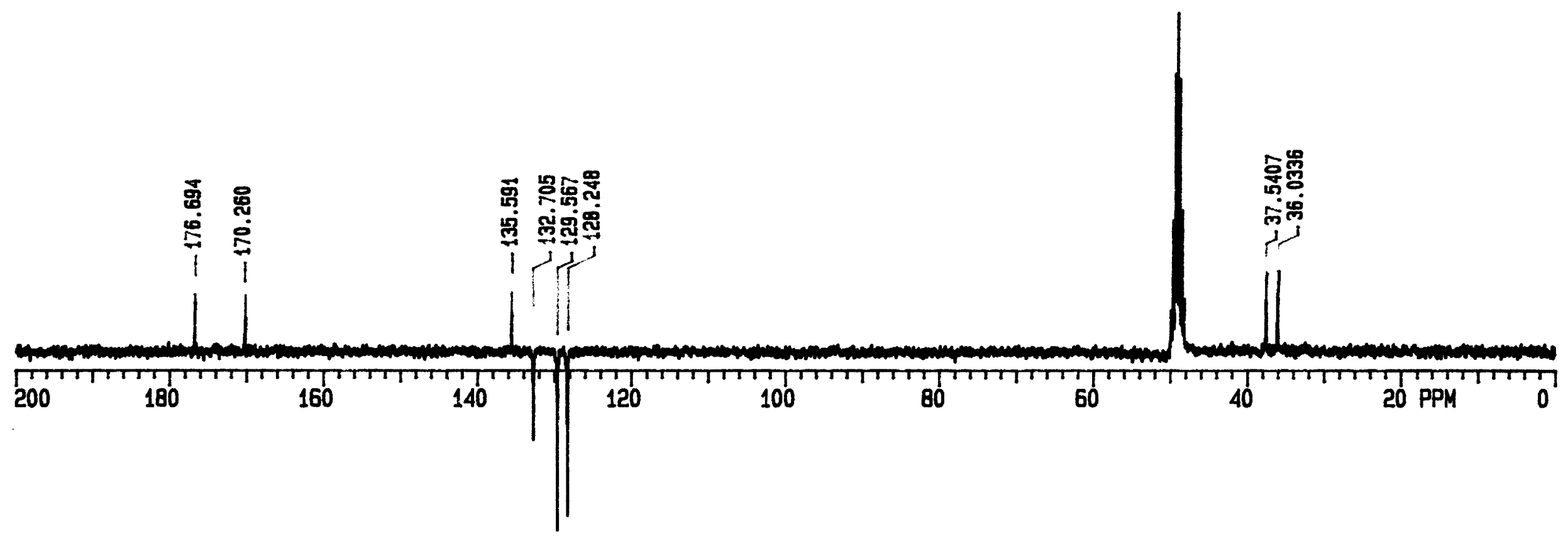




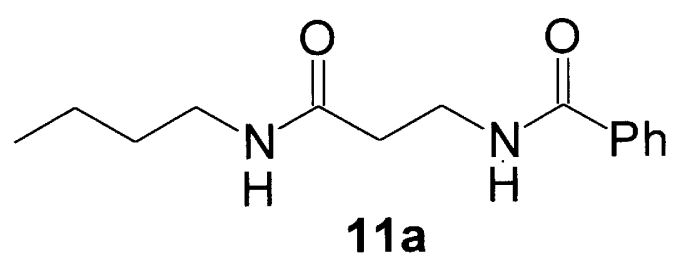

${ }_{1} \mathrm{H} \mathrm{NMR}(300 \mathrm{MHz})$ in $\mathrm{CD}_{3} \mathrm{OD}$

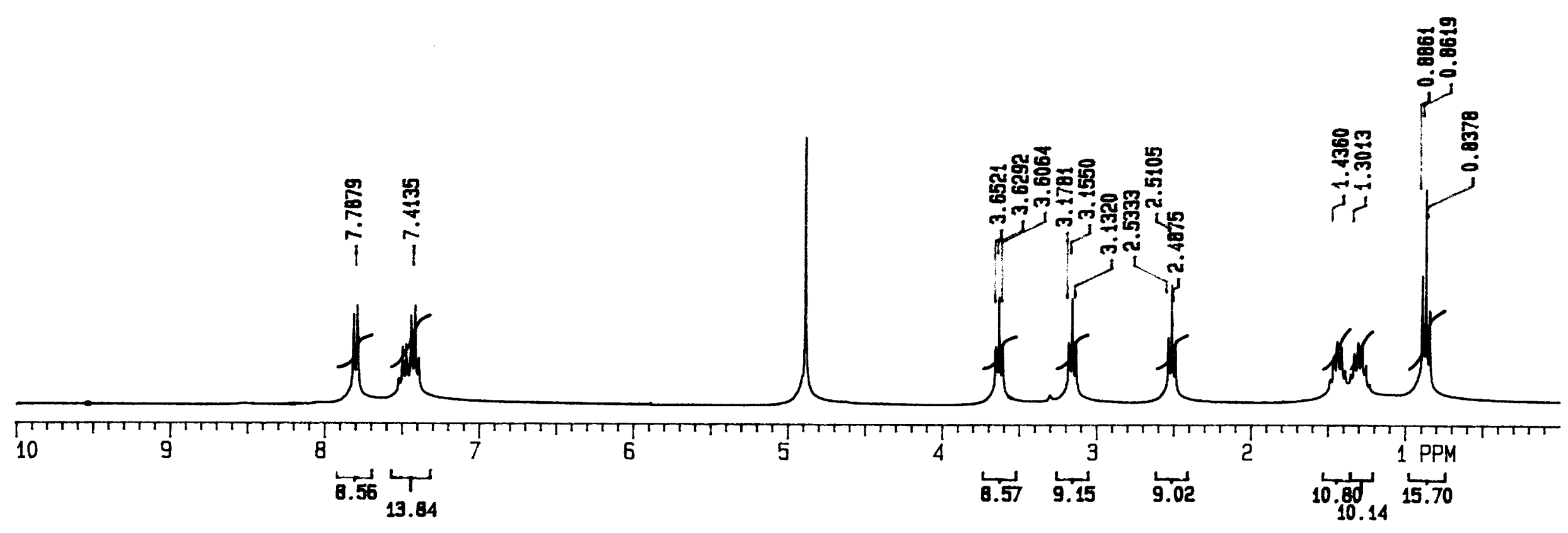




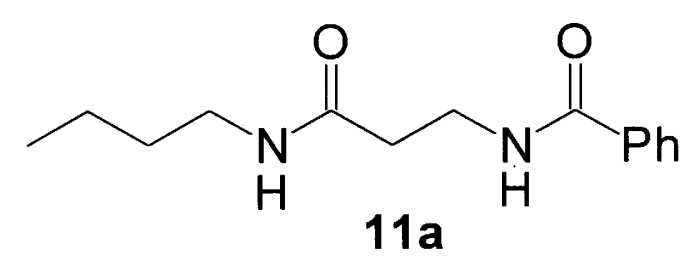

${ }^{13} \mathrm{C} \mathrm{NMR}(75 \mathrm{MHz})$ in $\mathrm{CD}_{3} \mathrm{OD}$

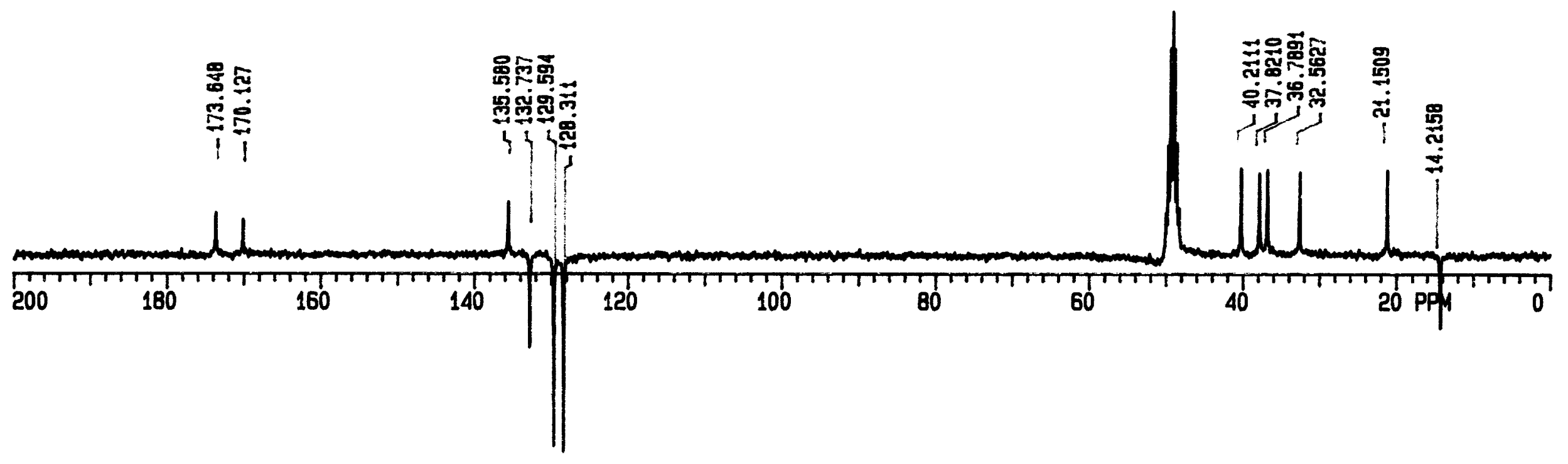

